\title{
Classifications in Brief: The Eaton-Littler Classification of Thumb Carpometacarpal Joint Arthrosis
}

\author{
Colin D. Kennedy MD, Mary Claire Manske MD, Jerry I. Huang MD
}

Received: 15 March 2016/Accepted: 22 April 2016/Published online: 4 May 2016

(C) The Association of Bone and Joint Surgeons(B) 2016

\section{History}

The thumb carpometacarpal (CMC) joint is a biconcave saddle joint between the thumb metacarpal and trapezium that allows for multiplanar movement. High compressive forces through the CMC joint, up to $120 \mathrm{~kg}$ with power grasp and $12 \mathrm{~kg}$ with tip pinch [8], may predispose this joint to degenerative arthritis. Arthritis of this joint more commonly occurs in women than in men, starting in middle adulthood and increasing in prevalence with age [14]; radiographic prevalence ranging from $33 \%$ of postmenopausal women [1] to as high as $100 \%$ of women older than 91 years is described [4]. The anterior oblique ligament incompetence has been shown to play a role in the progression of CMC arthritis [3, 7, 19, 20].

In 1967, Richard Eaton and William Littler developed a ligament reconstruction procedure for refractory thumb CMC arthritis that reinforced the joint capsule in two planes $[11,12]$. They subsequently described four progressive radiographic stages of CMC arthritis in 1973, which later was modified to include scaphotrapezial arthritis [10]. This modified Eaton-Littler classification is

\footnotetext{
Each author certifies that he or she has no commercial associations (eg, consultancies, stock ownership, equity interest, patent/licensing arrangement, etc) that might pose a conflict of interest in connection with the submitted article.

All ICMJE Conflict of Interest Forms for authors and Clinical Orthopaedics and Related Research ${ }^{\mathbb{R}}$ editors and board members are on file with the publication and can be viewed on request.
}

C. D. Kennedy ( $₫)$, M. C. Manske, J. I. Huang Department of Orthopaedics and Sports Medicine, University of Washington, 1959 N.E. Pacific St., Box 356500, Seattle, WA 98195-6500, USA

e-mail: colink2@uw.edu now the most commonly used radiographic classification system for basilar thumb arthrosis [10] (Table 1).

\section{Purpose}

Patients with refractory pain and functional limitations often are candidates for surgical intervention. Although Eaton and Littler described their radiographic classification to be used to guide surgical intervention [12], the radiographic presence of basilar thumb arthritis is nearly inevitable with age [4], and surgery should be considered only if extensive nonsurgical treatment options have been exhausted and lifestyle limiting pain and disability persists.

\section{Classification}

The Eaton-Littler classification describes four stages of CMC arthrosis based on a true lateral radiograph of the trapeziometacarpal joint of the thumb with the sesamoid bones superimposed on one another [10, 12].

Stage I arthrosis shows normal radiographs without joint space narrowing, cyst formation, or subchondral changes, but this stage instead might have joint space widening attributable to synovitis, effusion, or laxity of the CMC joint (Fig. 1A) [10]. This stage often is present in young women with generalized ligamentous laxity who have pain with use [3]. Eaton and Littler described this stage as the synovitis phase before the onset of more severe capsular laxity [12].

Stage II arthrosis features joint-space narrowing with osteophytes or loose bodies smaller than $2 \mathrm{~mm}$ in diameter (Fig. 1B). This stage often is seen in active women in the 
Table 1. The four stages of the Eaton-Littler classification

\begin{tabular}{ll}
\hline Stage & Description \\
\hline I & Subtle carpometacarpal joint space widening \\
II & Slight carpometacarpal joint space narrowing, sclerosis, and cystic changes with osteophytes or loose bodies $<2$ mm \\
III & Advanced carpometacarpal joint space narrowing, sclerosis, and cystic changes with osteophytes or loose bodies $>2$ mm \\
IV* & Arthritic changes in the carpometacarpal joint as in Stage III with scaphotrapezial arthritis \\
\hline
\end{tabular}

*Stage IV as modified by Eaton and Glickel [10].
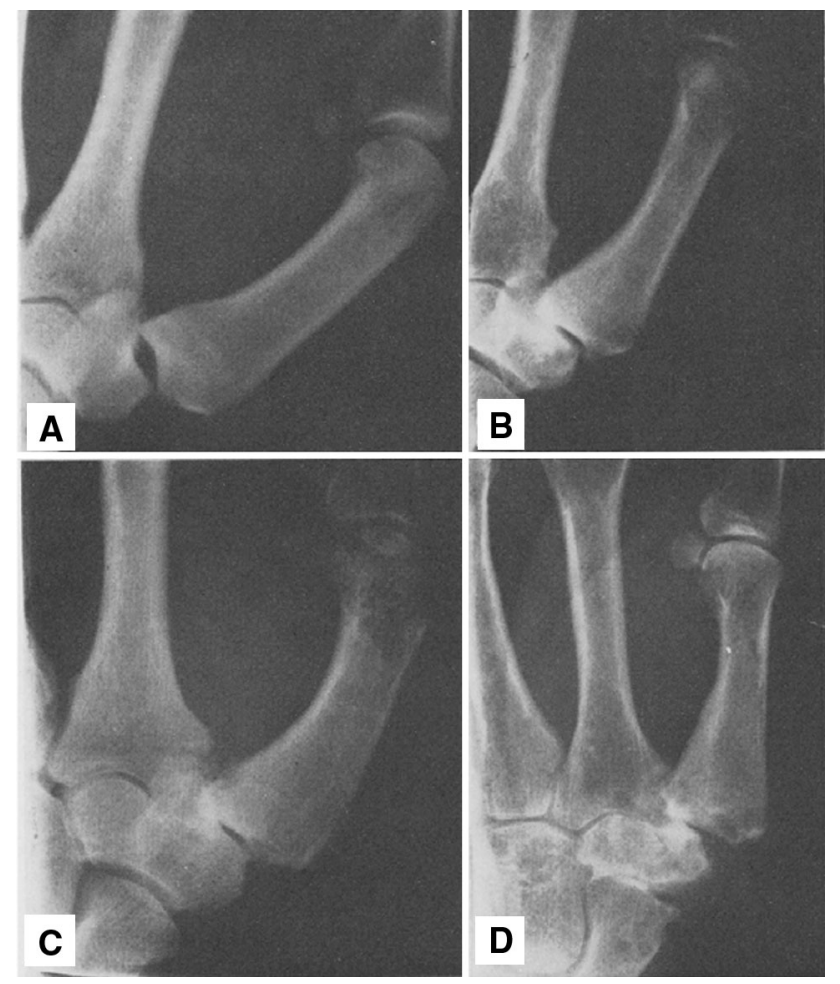

Fig. 1A-D Stages (A) I, (B) II, (C) III, and (D) IV carpometacarpal arthrosis of the Eaton-Littler classification system, and as described by Eaton et al. are shown. (Published with permission from Eaton EG, Lane LB, Littler JW, Keyser JJ. Ligament reconstruction for the painful thumb carpometacarpal joint: a long-term assessment. $J$ Hand Surg Am. 1984;9: 692-699.).

fourth and fifth decades of life [3]. Eaton and Littler described this stage as having at least $1 / 3$ CMC joint subluxation [12].

Stage III arthrosis features greater than $1 / 3$ subluxation of the CMC joint and osteophytes exceeding $2 \mathrm{~mm}$ in diameter (Fig. 1C) [12]. Marked joint space narrowing with sclerotic bone and cystic change often are present. At this stage, the scaphotrapezial joint remains well preserved. Stage III arthrosis often is seen in females in the fifth through seventh decades of life [3].

Eaton and Littler originally described Stage IV CMC arthrosis with advanced degenerative changes, including substantial subluxation, joint space narrowing, and subchondral cysts and sclerosis (Fig. 1D). They stated that this stage was "generally applicable to rheumatoid arthritis" [12]. This stage later was modified by Eaton and Glickel as showing deterioration of the CMC joint, as in Stage III arthrosis, but with the addition of joint space narrowing and cystic or sclerotic changes in the scaphotrapezial joint [10].

\section{Validation}

The earliest attempts at validation of their classification system came with Eaton and Littler's treatment followup results. The procedure described by Eaton and Littler for flexor carpi radialis tendon reconstruction was successful in patients with Stages 1 or 2 arthritis but not for more severe stages. Eaton and Littler originally described 18 patients with thumb CMC arthritis treated with flexor carpi radialis reconstruction using a strip of the flexor carpi radialis tendon to reconstruct the anterior oblique ligament [12]. All patients in their series with Stages I or II arthritis had excellent results (defined as no pain, grip strength equal to or within $10 \%$ of the contralateral side, and no additional deterioration of articular surfaces) at an average 2.5 years after reconstruction. Five of eight patients $(62.5 \%)$ with Stage III arthritis were described as having excellent results at an average 30 months after surgery. Flexor carpi radialis reconstruction in patients with Stage IV arthritis was less successful, with one of five patients (20\%) with Stage IV arthritis meeting the described excellent criteria after flexor carpi radialis reconstruction, and Eaton and Littler recommended arthroplasty or arthrodesis as more appropriate procedures at this advanced stage [12]. In a later study, Eaton et al. [11] described 50 patients treated with the flexor carpi radialis reconstruction procedure, at an average 7 years follow up, and reported that 18 of 19 patients (95\%) with Stages I or II arthritis had good or excellent results (with "excellent" defined as no pain, pinch strength greater than $90 \%$ of the contralateral thumb, and minimum laxity, and "good" defined as occasional pain after prolonged activity, pinch strength greater than $70 \%$ of the contralateral thumb, and minimum laxity) with flexor carpi radialis reconstruction whereas 14 of 19 patients (74\%) with Stages 
III or IV arthritis achieved good or excellent results. Based on these two studies, Eaton and Littler concluded that the outcomes of flexor carpi radialis reconstruction were directly related to the extent of articular damage, and better outcomes are achieved when surgery is performed before the onset of more severe articular damage. They recommended flexor carpi radialis ligament reconstruction only for patients with Stages I or II CMC arthritis.

Reliability of the Eaton-Littler classification is moderate at best, and its utility for guiding treatment appears to be poor. In 40 cases evaluated by five muscuoloskeletal radiologists and eight hand surgeons, Spaans et al. [22] reported only moderate interobserver reiability $(\kappa=0.496)$; and when choosing treatment options, the surgeons chose the same treatment option in only four of the 40 cases $(10 \%)$, illustrating the wide variability in classifying and treating thumb CMC arthritis. Similarly, Kubik and Lubahn [15] assessed the intraobserver and interobserver reliability of the Eaton-Littler classification using 40 radiographs that were evaluated by three hand surgeons and three orthopaedic surgery residents, finding only moderate interobserver agreement $(\kappa=0.529)$. Berger et al. [6] conducted a systematic review of four studies on the intra- and interobserver reliability of the Eaton-Littler classification and found poor to fair interobserver reliability $(\kappa=0.11-0.56)$ and fair to moderate intraobserver reliability $(\kappa=.54-0.66)$. Interestingly, Becker et al. [5] found that eliminating evaluation of the scaphotrapezial joint and thus shortening the Eaton-Littler classification to three stages improved the interobserver reliability among 92 hand surgeons. They also stated that providing clinical information to the raters improved interobserver reliability [5], suggesting that surgeon and patient factors can bias interpretation of objective data such as radiographic findings.

\section{Limitations}

Although widely adopted, the Eaton-Littler classification of thumb CMC arthrosis has several limitations, including (1) the difficulty in profiling the thumb CMC joint radiographically, (2) the discrepancy between radiographic appearance, intraoperative findings, and clinical symptoms, and (3) the limited ability of this classification system to guide treatment.

First, the orientation of the thumb presents radiographic challenges in the assessment of arthrosis owing to the obliquity of the trapezium in the coronal and sagittal planes [9]. North and Eaton [18] reported that the radiographs of the scaphotrapezial articulation, in particular, were capable of under- and overdiagnosing arthritic degeneration compared with anatomic inspection of these joints, and suggested that the principle reason for this discrepancy is the presence of overlapping osteophytes at the trapezium and index metacarpal joint. Methods for improving the diagnostic accuracy and staging of CMC arthrosis have been proposed. Eaton and Littler [12] described a stress view that assesses stability of the CMC ligaments and provides improved observation of the trapezial facets. Additional radiographic views have been described [9, 10, 18, 25]. The Robert's view (Fig. 2) is a true AP view of the thumb taken with the wrist in maximal pronation with the dorsum of the thumb parallel to the table in which the beam is centered on the trapeziometacarpal joint $[13,16]$. The Bett's (Gedda's view) view is taken with the hand pronated $30^{\circ}$ and the imaging beam directed obliquely in a distal to proximal direction and centered over the trapeziometacarpal joint to improve observation of the pantrapezial joints (Fig. 3). In only one study, adding the Bett's view to the posteroanterior (PA) and lateral views led to the highest inter- and intraobserver agreement as opposed to using only the PA and lateral views or Bett's view alone [9].

The Eaton-Littler classification has not been shown to correlate with clinical symptoms, which is what motivates most patients to seek treatment. Hoffler et al. [14] prospectively reviewed 62 patients with unilateral basilar thumb arthritis, and reported there was no correlation between the Eaton-Littler stage and patient-reported symptom scores. In a radiographic review of 2321 patients, Becker et al. [4] found an age-related increase in the radiographic prevalence of $\mathrm{CMC}$ thumb arthrosis to be as much as $100 \%$ in women older than 91 years and $93 \%$ in men 81 years or older, yet only three patients $(0.1 \%)$

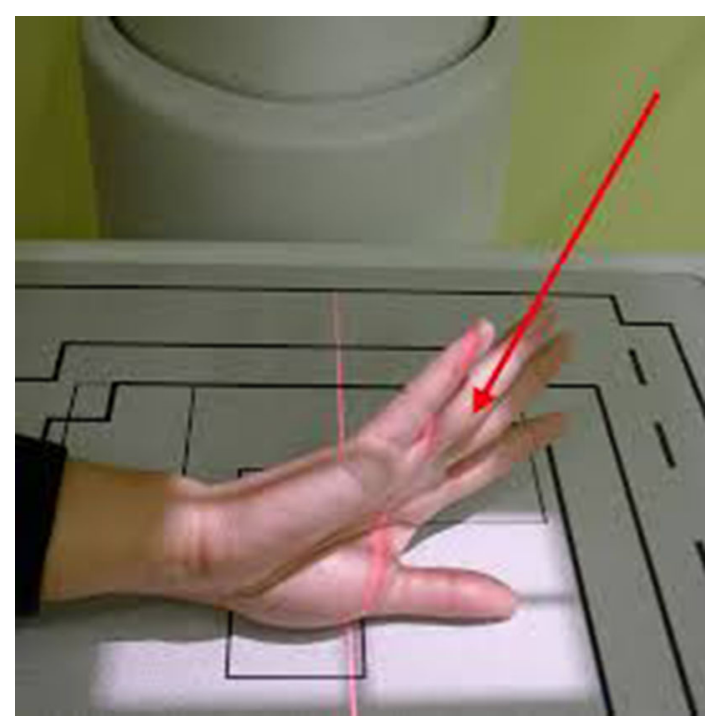

Fig. 2 The Robert's view radiograph [16] is taken with the wrist in maximal pronation, with the dorsum of the thumb parallel to the table, and the imaging beam is centered on the trapeziometacarpal joint (Published with permission from Amy L. Ladd MD.). 


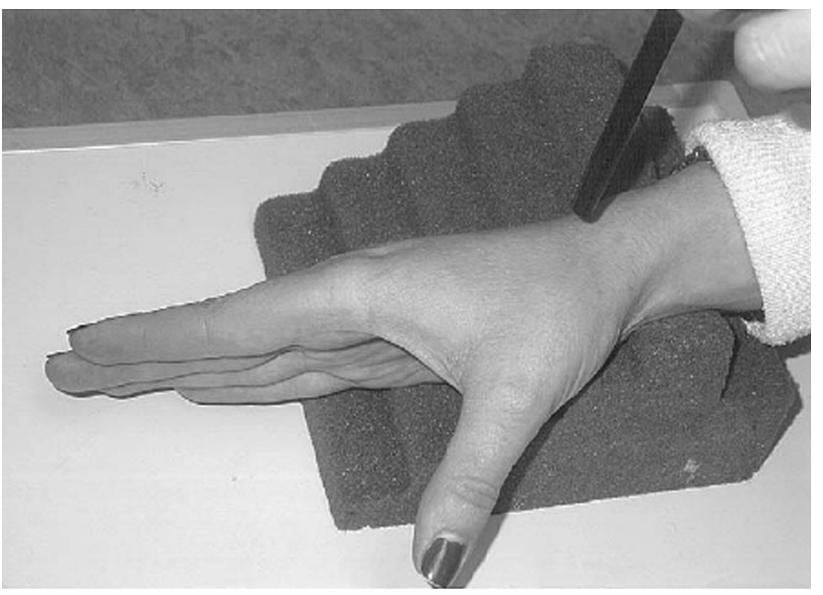

Fig. 3 The Bett's view (Gedda's view) radiograph is taken with the hand pronated $30^{\circ}$ and the imaging beam directed obliquely in a distal to proximal direction and centered over the trapeziometacarpal joint. (Published with permission from Dela Rosa TL, Vance MC, Stern PJ. Radiographic optimization of the Eaton classification. J Hand Surg Br. 2004;29:73-177.).

required exclusion from the study owing to prior surgery. They [4] postulated that despite the high prevalence of CMC thumb arthritis, most people adapt to this nearly inevitable aspect of aging. Additionally, the Eaton-Littler classification assumes a stepwise progression of CMC arthrosis from one stage to the next, which may be an incorrect presumption particularly between Stage III and IV as illustrated by the ability for scaphotrapezial arthrosis to exist independently of CMC arthrosis and for severe CMC arthrosis to exist in the absence of scaphotrapezial arthrosis. There is also the potential for redundancy between stages, such as the ability for a patient to have radiographic features of more than one stage of the classification at the same time.

Although radiographic appearance has predictive value for operative decision making, clinical symptoms and intraoperative findings may be more reliable in determining which treatment option will most benefit a patient. Arthroscopic evaluation of the CMC joint and advanced imaging studies have been described but have not reached widespread use [2, 17, 21]. Badia [2] proposed a threestage arthroscopic classification system of the thumb CMC joint that he thought could be used to guide surgical decision making. He emphasized that arthroscopic evaluation of the thumb CMC joint allows for direct assessment of structures not observed well on radiographs, such as synovium, articular cartilage, and the joint capsule and that this observation is useful in circumstances where the extent of arthrosis is difficult to ascertain using only radiographs. Although not routinely used in the evaluation of patients with basilar thumb pain, MRI and ultrasound can be used to provide tridimensional diagnostic information of the thumb $\mathrm{CMC}$ joint including the integrity of the anterior oblique ligament [17]. Saltzherr et al. [21] described higher interobserver reliability for thumb CMC and scaphotrapezial arthrosis on CT imaging compared with radiographs, which could influence surgical decision making. With all stages of CMC arthritis, severity of radiographic changes may not necessarily correlate with the surgeon's preferred treatment options, which vary extensively without clear evidence of superiority of one surgical option over others [23, 24].

\section{Conclusions}

The Eaton-Littler classification of thumb CMC arthrosis is a widely used classification system that describes basilar thumb arthritis in four progressive radiographic stages. Studies have shown only moderate to weak reliability, little correlation with treatment choices that clinicians make [6, 15, 22], and poor correlation between the Eaton-Littler stage and symptom severity [4, 14]. In addition, wide variation exists among surgeon preference for the surgical management options of basilar thumb arthritis [23, 24], and treatment options are not easily dictated by the four EatonLittler stages. Although the classification is useful for describing the radiographic progression of thumb CMC arthrosis, it is more of historical interest and its clinical utility is limited. Alternate categorizations that correlate anatomic disorders and features to symptom severity and correlate with patient-reported validated outcome measures are needed.

\section{References}

1. Armstrong AL, Hunter JB, Davis TR. The prevalence of degenerative arthritis of the base of the thumb in post-menopausal women. J Hand Surg Br. 1994;19:340-341.

2. Badia A. Trapeziometacarpal arthroscopy: a classification and treatment algorithm. Hand Clin. 2006;22:153-163.

3. Barron OA, Catalano LW. Thumb basal joint arthritis. In: Wolfe SW, Pederson WC, Hotchkiss RN, Kozin SH, eds. Green's Operative Hand Surgery. $6^{\text {th }}$ ed. Philadelphia, PA: Elsevier Churchill Livingstone; 2011:407-426.

4. Becker SJ, Briet JP, Hageman MG, Ring D. Death, taxes, and trapeziometacarpal arthrosis. Clin Orthop Relat Res. 2013;471:3738-3744.

5. Becker SJ, Bruinsma WE, Guitton TG, van der Horst CM, Strackee SD, Ring D; Science of Variation Group. Interobserver agreement of the Eaton-Glickel classification for trapeziometacarpal and scaphotrapezial arthrosis. J Hand Surg Am. 2016 Jan 27. pii: S0363-5023(15)01631-7. doi: 10.1016/ j.jhsa.2015.12.028. [Epub ahead of print]

6. Berger AJ, Momeni A, Ladd AL. Intra- and interobserver reliability of the Eaton classification for trapeziometacarpal arthritis. Clin Orthop Relat Res. 2014;472:1155-1159.

7. Burton RI, Pellegrini VD Jr. Surgical management of basal joint arthritis of the thumb. Part II: ligament reconstruction with tendon interposition. J Hand Surg Am. 1986;11:324-332. 
8. Cooney WP 3rd, Chao EY. Biomechanical analysis of static forces in the thumb during hand function. J Bone Joint Surg Am, 1977;59:27-36.

9. Dela Rosa TL, Vance MC, Stern PJ. Radiographic optimization of the Eaton classification. J Hand Surg Br. 2004;29:173-177.

10. Eaton EG, Glickel SZ. Trapeziometacarpal osteoarthritis: staging as a rationale for treatment. Hand Clin. 1987;3:455-471.

11. Eaton EG, Lane LB, Littler JW, Keyser JJ. Ligament reconstruction for the painful thumb carpometacarpal joint: a long-term assessment. J Hand Surg Am. 1984;9:692-699.

12. Eaton EG, Littler JW. Ligament reconstruction for the painful thumb carpometacarpal joint. J Bone Joint Surg Am. 1973;55: $1655-1666$

13. Giladi AM, Wang Y, Chung KC. Radiologic studies used in evaluation of the upper extremity. In: Chung KC, ed. Essentials of Hand Surgery. $1^{\text {st }}$ ed. London, UK: Jp Medical Ltd; 2015:2131.

14. Hoffler CE 2nd, Matzon JL, Lutsky KF, Kim N, Beredjiklian PK. Radiographic stage does not correlate with symptom severity in thumb basilar joint osteoarthritis. J Am Acad Orthop Surg. 2015; 23:778-782.

15. Kubik NJ 3rd, Lubahn JD. Intrarater and interrater reliability of the Eaton classification of basal joint arthritis. J Hand Surg Am. 2002;27:882-885.

16. Ladd AL. Guest editorial: The Robert's view: a historical and clinical perspective. Clin Orthop Relat Res. 2014;472:10971100 .

17. Melville DM, Taljanovic MS, Scalcione LR, Eble JM, Gimber LH, DeSilva GL, Sheppard JE. Imaging and management of thumb carpometacarpal joint osteoarthritis. Skeletal Radiol. 2015;44:165-177.
18. North ER, Eaton RG. Degenerative joint disease of the trapezium: a comparative radiographic and anatomic study. $J$ Hand Surg Am. 1983;8:160-166.

19. Pellegrini VD Jr. Osteoarthritis of the trapeziometacarpal joint: the pathophysiology of articular cartilage degeneration. I: anatomy and pathology of the aging joint. J Hand Surg Am. 1991;16:967-974.

20. Pellegrini VD Jr. Osteoarthritis of the trapeziometacarpal joint: the pathophysiology of articular cartilage degeneration. II: articular wear patterns in the osteoarthritic joint. J Hand Surg Am. 1991;16:975-982.

21. Saltzherr MS, van Neck JW, Muradin GS, Ouwendijk R, Luime JJ, Coert JH, Hovius SE, Selles RW. Computed tomography for the detection of thumb base osteoarthritis: comparison with digital radiography. Skeletal Radiol. 2013;42:715-721.

22. Spaans AJ, van Laarhoven CM, Schuurman AH, van Minnen LP. Interobserver agreement of the Eaton-Littler classification system and treatment strategy of the thumb carpometacarpal joint arthritis. J Hand Surg Am. 2011;36:1467-1470.

23. Vermeulen GM, Slijper H, Feitz R, Hovius SE, Moojen TM, Selles RW. Surgical management of primary thumb carpometacarpal osteoarthritis: a systemic review. J Hand Surg Am. 2011;36:157-169.

24. Wajon A, Vinycomb T, Carr E, Edmunds I, Ada L. Surgery for thumb (trapeziometacarpal joint) osteoarthritis. Cochrane Database Syst Rev. 2015;2:CD004631.

25. Wolf JM, Oren TW, Ferguson B, Williams A, Petersen B. The carpometacarpal stress view radiograph in the evaluation of trapeziometacarpal joint laxity. J Hand Surg Am. 2009;34:14021406. 